\title{
The importance and challenges of crop germplasm interdependence: the case of Bhutan
}

\author{
Mahesh Ghimiray $^{1} \cdot$ Ronnie Vernooy ${ }^{2}$
}

Received: 25 January 2016 / Accepted: 2 January 2017 /Published online: 25 February 2017

(C) The Author(s) 2017. This article is published with open access at Springerlink.com

\begin{abstract}
An analysis of food crop germplasm flows into and out of Bhutan was carried out to determine the extent of reliance of Bhutanese agriculture on introduced germplasm. Methods used included literature review, key informant interviews, field visits and crop pedigree analysis. Bhutan has been introducing foreign germplasm since the 1960s. By December 2015, about 300 varieties of 46 food crops including several non-traditional crops were introduced. Germplasm sources include CGIAR centres such as IRRI, CIMMYT, ICARDA, and AVRDC and countries such as Bangladesh, India, Japan, Korea, Nepal, and Thailand. Pedigree analysis of rice varieties indicated that $74 \%$ of the released varieties originated in other countries. Using imported germplasm, Bhutan has formally released over 180 varieties of cereals, fruits and vegetables. Initially, the germplasm flow was largely unregulated, but the country has been developing formal exchange mechanisms with the creation of the National Biodiversity Centre (NBC) in 1995. Findings point to a strong reliance on external germplasm for the country's major food crops. International germplasm exchanges will remain important to deal with new environmental and climatic conditions and given the limited national plant breeding capacity. National agricultural policy should give higher priority to collaborative development of new crops in the Himalayan region and beyond.
\end{abstract}

Ronnie Vernooy

r.vernooy@ cgiar.org

Mahesh Ghimiray

mghimiray@gmail.com

1 Renewable Natural Resources Research and Development Centre, Bajo, Bhutan

2 Policy, Institutions and Monitoring, Bioversity International, Via dei Tre Denari 472A, 00057 Maccarese, Italy
Keywords Biodiversity $\cdot$ Crop germplasm $\cdot$ Food security · Interdependence $\cdot$ Multilateral system $\cdot$ Pedigree analysis

\section{Introduction}

No country in the world is self-sufficient in germplasm to fulfill its food requirements. Most major agricultural crops evolved over a period of thousands of years in the developing countries which have the greatest concentration of genetic diversity. Many countries heavily depend on non-indigenous crops and imported germplasm for food and agricultural development (Fowler et al. 2000). Today, all countries and all regions have become highly interdependent (Galluzzi et al. 2015; Khoury et al. 2016). In order for countries to successfully adapt to climate change it is expected that this interdependency will further increase (Reynolds 2010; Yadav et al. 2011). Modern-day germplasm flows are not necessarily associated positively with historic centers of diversity, but find their sources in international and national genebanks and breeding programs based in other parts of the world. Bhutan is a good example of a country that has been and continues to be highly interdependent in this regard in particular concerning its major food crops. An analysis of the historical evolution of interdependency contributes to a better understanding of the particular political economy of Bhutan. It also provides insights helpful in developing more effective germplasm exchange strategies for today and tomorrow.

Bhutan is a small landlocked country located in the southern Eastern Himalayas which for centuries has largely remained isolated from the rest of the world. Agriculture is the mainstay of the people with an estimated $70 \%$ of the population engaged in farming and related activities. Rice, maize, wheat, barley, buckwheat and millets are the major cereal crops cultivated. Rice, maize, and wheat are the country's 
major food crops. The majority of Bhutanese farmers continue to practise a largely self-sustaining, integrated and subsistence-oriented agricultural production system, growing a variety of major and minor crops and raising livestock to meet household food security needs. Over centuries, farmers have selected and cultivated a wide array of crops and crop varieties that have adapted well to the many micro-climatic and agroecological niches in the country. In the 1960s, however, the government of Bhutan started the promotion of new, modern crops and crop varieties in order to meet increasing food demand. The research and extension system of the Department of Agriculture is geared towards finding and promoting new high yielding crop varieties in an effort to enhance production, reduce food and input imports and improve food sufficiency and security. Among the impacts of this push toward modern varieties has been the displacement of genetically diverse farmer cultivars by a few modern bred varieties that have a narrow genetic base. An adoption study of new rice varieties in 2010 indicated that $42 \%$ of the total rice area in the country was cultivated with modern varieties, in particular in the altitudes below $1800 \mathrm{~m}$ above sea level (Ghimiray 2012). Production is dominated by three varieties (IR64, Khangma Maap and BR153). Similarly, 49\% of the maize area is occupied by modern varieties dominated by a single variety Yangtsipa. There are no studies on wheat, but estimates made by interviewed agricultural specialists suggest that the adoption rate of modern cultivars is very high in the wetland systems where wheat is grown. As a result and perhaps surprisingly, Bhutanese subsistence farming relies strongly on the use of modern varieties.

Green revolution technologies have been promoted in Bhutan since the start of the government's so-called planned development period. New high yielding varieties that were available in India were introduced and their seed multiplied on government farms and then supplied to farmers. A few of these varieties (e.g. wheat variety Sonalika, rice variety IR8) are still prevalent among farmers. Along with the seeds, synthetic fertilizers and agro-chemicals were popularized. In addition, large irrigation channels were built. However, the rate of success was not as high as in India where more uniform tropical environments prevail. Bhutan is characterized by a high diversity of agro-ecological conditions, diverse farming systems, subsistence agriculture and low technology absorption capacity of farmers. These features explain the lower rate of the adoption of green revolution technologies and techniques.

The overall policy objectives of the Royal Government of Bhutan for biodiversity are that biodiversity issues will be integrated into the economic development plans and programs, special attention will be given to support parks and protected areas and effective buffer zones management, and information on biological diversity will be developed for conservation and sustainable utilization of biodiversity resources.
There are no specific policies designed to conserve, utilize and protect the rich agro-biodiversity of the country. In general, Bhutan's agricultural policies favor and focus on the production of a few uniform modern varieties of crops in favorable pockets supported by intensive input use and a technical support package approach. Policies lack an analysis of the impact of this approach on on-farm genetic diversity. The notion that economic benefits can be derived only from the promotion of modern varieties and associated technologies still dominates the policy formulation process. Current agricultural and economic policies focus on introduction and promotion of major crops and modern varieties ignoring the suitability and potential of local landraces, including their potential to adapt more effectively to climate change.

The green revolution and the modernization of Bhutanese agriculture were made possible due to the introduction of foreign germplasm. This paper analyzes, in the following sections, the patterns and trends of germplasm flows into and out of Bhutan, the extent of its reliance on external germplasm for the country's major food crops and agriculture, the use of imported germplasm in Bhutanese crop improvement programs, the use of Bhutanese germplasm in variety innovations, and factors influencing germplasm exchange and constraints and opportunities in accessing germplasm. The analysis is enriched by a case study of rice varieties released in Bhutan. Pedigree analysis is a useful tool to determine the degree of the country's reliance on germplasm from other countries. Such an analysis of the historical evolution of interdependency can provide insights to develop more effective germplasm exchange strategies for today and tomorrow. As far we know this study is the first of its kind in Bhutan.

\section{Methods and materials}

The present study on germplasm flows relied on i) a review and analysis of available literature (both published and unpublished) and reports, ii) visits to different institutions such as research centers (the country's Renewable Natural Resource Research and Development Centers or RNR-RDCs), seed production farms (National Seed Centre or NSC) to collect information and interact and interview with scientists, administrators and managers and iii) interviews with individual experts (some of them retired) in the field of agriculture and plant genetic resources to obtain information that is unavailable in written or published form. The review of literature and technical reports included annual technical reports of RNR-RDCs, proceedings of research meetings and workshops, research publications of RNR-RDCs, consultant reports, journal publications and other internal reports of institutions in Bhutan in addition to international literature provided by Bioversity International. No previous study of crop germplasm flows and interdependency could be found. Four 
RNR-RDCs namely Bajo, Jakar, Bhur and Wengkhar were visited in order to interact with research colleagues. The visits also included a trip to the NSC head office in Paro. For pedigree analysis, pedigree information on released varieties from the International Crop Information System (ICIS) was extracted with the collaboration of Dr. Madan Bhatta and Dr. B.K. Joshi of the National Agriculture Research Council of Nepal. Varieties of nationally important crops in Bhutan like rice were used for the pedigree study. Review of country and crop specific pedigree literature was done in addition to interviews with crop breeders in the RNR-RDCs.

\section{Results}

Agricultural research in Bhutan started with the introduction of exotic crop varieties and modern cultivation methods aimed to increase production. Among the existing institutions, the RNR-RDCs are the oldest dealing with crop improvement research. The RNR-RDCs, which are under the Department of Agriculture, are actively involved in development and utilization of crop genetic resources in field crops and horticulture (Ghimiray and Katwal 2013). The RNR-RDCs are assigned specific commodities such as rice, maize, fruits and vegetables. They maintain small germplasm collections and tree mother field blocks for the regeneration of seed. The NSC handles larger amounts of crop germplasm including that of potato mainly for marketing purposes.

The germplasm flow into the country is facilitated by the RNR-RDCs while the overall regulation is provided by the National Biodiversity Centre (NBC). Each RNR-RDC, with the given national mandate (for instance, RNR-RDC Bajo for cereals and RNR-RDC Wengkhar for horticultural crops) links with relevant CGIAR centers or with regional research centers to obtain germplasm. These focal RNR-RDCs then supply relevant germplasm to other RNR-RDCs for testing and adaptation. Apart from the RNR-RDCs, germplasm is also brought in by donor-assisted projects involved in agricultural development. For instance, a UNDP supported horticultural development project and a JICA (Japan) project were instrumental in securing germplasm of fruits, nuts, vegetables and cereals.

For Bhutanese germplasm to flow out of the country, NBC serves as the nodal agency and requires established procedures to be completed before samples move out. The patterns of germplasm flow into and out of the country have changed over time. Initially, with the commencement of research in the 1980s, a lot of germplasm was brought in for quick testing and release of varieties. Several tested germplasms were released as varieties for different agro-ecosystems. Now the amount of germplasm flowing in has decreased slightly. Within the country, the pattern of germplasm flow has not changed very much. Germplasm flow out of the country was greater in the past, prior to the creation of NBC. This was mainly because of the lack of regulations in place. Nowadays the outflow has decelerated.

\section{Inflow of germplasm}

Although the history of formal agricultural research in Bhutan is relatively young, since institutionalized research started only in 1982, a considerable amount of germplasm flow has occurred in the country. Altogether, as of December 2015, a total of 46 different crops and 297 varieties have been introduced and imported into the country. The main staple food crops of Bhutan are rice, maize and wheat. Introduced varieties tested and released in the country are gradually displacing the traditional landraces. In rice, $42 \%$ of the area is under improved varieties (Shrestha 2004). Imported varieties of maize cover $49 \%$ of the area (Shrestha et al. 2006). All wheat varieties in the main irrigated wetland system are recent introductions.

The RNR-RDCs are the primary institutes involved in crop improvement research. As the findings of the research indicate, these institutes rely heavily on external sources for their crop improvement programs. New germplasm is introduced, tested and if found suitable, directly released as varieties so that farmers can access them. In a few cases, introduced germplasm is also used in crop breeding programs. Rice is an example where IRRI germplasm is used to develop local varieties for disease tolerance and high yield. The extent of reliance on foreign sources varies from crop to crop. For instance, there is about $50 \%$ reliance on imported germplasm of rice and maize. All spring wheat varieties grown in the country are introduced. There is less reliance on secondary crops such as buckwheat, barley, millets and oil crops. In horticultural crops, both fruits and vegetables, the extent of reliance is estimated at $70-80 \%$ as most crops and varieties are relatively new introductions in the country. There is no local germplasm of crops such as hazel nut, pecan nut, apples, cabbages, grapes and avocado and thus there is total reliance on imported germplasm for these.

The agricultural research and development system has so far developed and released over 180 varieties of cereals, fruits and vegetables (CoRRB 2009). These include 41 varieties of cereals, oil crops and grain legumes, 75 varieties of 28 vegetable crops and 65 varieties of 22 fruit crops. Except for eight varieties of rice that were bred locally, all the other varieties are direct introductions from other countries and research institutes. Such varieties, developed elsewhere, were introduced, evaluated and released for cultivation in Bhutan.

Among cereals, rice is the most important staple food of the Bhutanese people. Although there are no precise historical records of its introduction, rice must be one of the earliest cultivated food crops in Bhutan (Dorji et al. 2015). Records 
of the Bondey farm indicate that the first introduced modern rice variety was a Japonica variety named No 11 from Japan in 1968. This variety is still popular in the temperate regions of the country. New rice germplasm started to flow into the country in 1984 when collaboration with the International Rice Research Institute (IRRI) was established. The flow of rice germplasm still continues averaging about 300 new breeding lines and varieties from the international rice nurseries of IRRI per year. Research in maize started in the early 1990s. Through links with the International Maize and Wheat Improvement Centre (CIMMYT) the flow of maize germplasm began and every year about 100 new materials are brought into the country for testing on station and on-farm.

New germplasm of wheat came to Bhutan as early as 1972 in the form of the Sonalika variety, one of the most successful stories of the Green Revolution. When formal links were made with CIMMYT, wheat germplasm from international test nurseries was introduced. This type of germplasm exchange continues at the present time. Apart from CIMMYT, wheat germplasm has also come from neighboring countries such as India and Nepal. New germplasm of millets from India and barley from the International Center for Agriculture in the Dry Areas (ICARDA) were introduced. This collaboration with international research centers is very important for the country given the very limited plant breeding capacity that exists there.

Hybridization of traditional Bhutanese rice cultivars with improved varieties or lines was started in the middle of the 1980 s as a longer term strategy for the improvement of Bhutanese rice varieties. The Bhutanese rice varieties are low yielding and response to added inputs is limited due to lodging and disease. However, they are valued for their yield stability and grain quality. The principal objective of the cross breeding program is to assimilate desirable genes for high yield, adaptability, grain quality, cold tolerance and disease resistance from various sources. To date, over 150 crosses have been made involving traditional Bhutanese varieties and improved breeding lines and/or varieties from elsewhere (Ghimiray 2005). More than 60 popularly grown varieties from the high and mid-altitude rice growing zones were used as local parents. RDCs have cross bred and developed 8 rice varieties which are better adapted to local conditions.

The appropriateness of foreign varieties of rice in the high altitude ecosystem of Bhutan is less certain. This ecosystem covers an altitude range of 1800 to $2800 \mathrm{~m}$ above sea level and has very specific environmental and climatic conditions. Experience has shown that imported germplasm, particularly from IRRI, fails to meet the local requirements of cold tolerance, earliness, blast resistance and grain quality (medium amylose). The effective flow of imported germplasm to this ecosystem has been limited. Rice germplasm from similar temperate environments of Japan, South Korea, northern China and the hills of Nepal is known to be more suitable.
However, accessing germplasm from these countries has been very difficult in the absence of effective institutional collaboration which has not received high priority in the national agricultural policy. At the same time, national efforts to improve local varieties for the higher altitudes, for example through participatory variety selection, have been very limited.

New crops also include sub-tropical fruits and nuts, vegetables, cereals, oil crops and grain legumes. Among the subtropical fruits and nuts, many new crops such as almond, grapes, figs, loquat, olive and litchi have been introduced. Germplasm of various citrus such as mandarin, lime and lemon for testing as well as for rootstock purposes has been acquired. The main sources of germplasm have been Europe, Japan, Thailand, Australia and India for temperate and sub-tropical fruits and nuts. The country has also imported new germplasm of non-traditional crops such as mango, avocado and olive. Pakistan, India, Nepal, Japan and Bangladesh are the major sources of germplasm for oil crops and grain legumes.

Traditionally, vegetables in Bhutan were limited to a few crops such as chili, green leaf, leaf onion, radish and beans. A demonstration farm was established in Bondey, Paro in 1966 with the assistance of the Japanese government and, for the first time, new vegetables such as Chinese cabbage, cabbage, tomato and pea were grown in the country. According to interviewees, the Bondey farm played an important role in international germplasm exchange, but only one unpublished manuscript could be retraced documenting its efforts (Anonymous Undated). With the start of vegetable research in the 1990s, foreign germplasm of many non-traditional crops such as cabbage, cauliflower, broccoli, Chinese cabbage, lettuce and asparagus has been successfully tested and is now grown in the country on a commercial scale. Vegetable germplasm has been sourced from Nepal, Japan, India, Taiwan (from the World Vegetable Centre or AVRDC), Thailand and USA. The country has one commercial vegetable seed company, but most of the seeds are imported from abroad (India in particular). While the biodiversity of vegetable crops has expanded and enriched the existing diversity and also contributed to the overall nutritional diversity in the country, the reliance on foreign sourced germplasm has increased at the same time.

\section{Pedigree analysis}

The germplasm flows presented so far are complemented with a case study of rice pedigree analysis. The main aim of pedigree analysis is to determine the international character of (new) varieties released and establish the extent of the country's reliance on sources from other countries and international organizations. Genetic diversity of varieties being cultivated helps to stabilize crop production because of its 
buffering effect on the development of new races of pathogens or insect pest biotypes. Genes controlling resistance are often localized in the nucleus, but some may be present in the cytoplasm as in the case of downy mildew resistance in corn for example. Thus, one of the approaches to study genetic diversity is to look at the nuclear and cytoplasmic background of the released varieties. Countries of origin of released varieties reflect nuclear diversity, based on the assumption that different countries utilize their own locally adapted materials (Javier 2007).

Since 1988, the National Seed Board of Bhutan has released 23 rice varieties for the high, mid and low altitude environments. The improved varieties originated from Japan, Nepal, China, Korea, Philippines, India and IRRI (Table 1). One introduction from Nepal named Chummrong is an IRRI-developed breeding line introduced in Nepal at an earlier time. Eight of the varieties released were developed by Bhutanese plant breeders, reflecting the RNR-RDC's capability to generate their own materials using limited resources.

The genetic history of the released varieties was traced back to the ancestral female parent (landrace) using the International Rice Information System. Paro China (introduced in Bhutan without passing through the formal channels) and No 11 (INGER-distributed germplasm believed to originate from Japan) have no pedigree records for genealogical analysis. The ancestral female parents identified for the remaining varieties were Cina, Aikoku, Local Maap, DunghanSahli, Tomoe Nishiki, Sikal PL1 and Jameli. The cytoplasmic sources are land races from Indonesia, Japan, Bhutan and one variety recorded with Hungary as origin (since Hungary does not have rice land races of its own this variety must have been accessed from the national genebank, but sourced from elsewhere). In general, the varieties released have wide cytoplasmic diversity.

Table 1 Varieties released in Bhutan for different agroecological zones from 1988 to 2010 and their pedigrees

\begin{tabular}{|c|c|c|c|c|}
\hline Release name & Year of release & Designation & Pedigree & Origin \\
\hline \multicolumn{5}{|l|}{ High altitude } \\
\hline No 11 & 1989 & Takanenishiki & --- & Japan \\
\hline KhangmaMaap & 1999 & Chummrong & A selection from landrace Ghandruk & Nepal \\
\hline Yusi Ray Maap & 2002 & IR62746-B-4-8-1-1 & Suweon 359//IR41996-118-2-3/ThimphuMaap & Bhutan \\
\hline \multirow[t]{2}{*}{ Yusi Ray Kaap } & 2002 & IR66068-B-B-31-2-1 & YR3825-11-3-2-3-1 & Bhutan \\
\hline & & & YR3825-11-3-2-1/Barkat & \\
\hline Jakar Rey Naab & 2006 & Paro China & --- & China \\
\hline Yusirey Kaap2 & 2010 & YP5-34-16 & Yakiyutaka/Naam & Bhutan \\
\hline Yusirey Maap2 & 2010 & YP6-35-21 & Yakiyutaka/Rey Maap & Bhutan \\
\hline \multicolumn{5}{|l|}{ Mid altitude } \\
\hline IR64 & 1988 & IR64 & IR5657-33-2-1/IR2061-465-1-5-5 & IRRI \\
\hline IR20913 & 1989 & IR20913-B-60 & IR7149-51-1-3/IR36//Paro White & IRRI \\
\hline \multirow[t]{2}{*}{ Milyang 54} & 1989 & Gayabyeo & Milyang 21/IR 32//Milyang 23 & Korea \\
\hline & & & /Milyang 30 & \\
\hline Barkat & 1992 & Barkat (K78-13) & Shinei/China 971 & India \\
\hline BajoMaap 1 & 1999 & CARD21-10-1-1-3-2-1 & Local Maap/IR64 & Bhutan \\
\hline BajoMaap 2 & 1999 & CARD21-14-1-1-3-2-1B & Local Maap/IR64 & Bhutan \\
\hline BajoKaap 1 & 1999 & IR61331-2-148-B & IR41996-118-2-1-3/Paro Maap & Bhutan \\
\hline BajoKaap 2 & 1999 & IR61328-1-136-2-1-2-3 & IR41996-118-2-1-3/BjaNaab & Bhutan \\
\hline Wengkhar Rey Kaap 2 & 2002 & Khumal 2 (NR168) & Jarneli/Kn-LD-361-DLK-2-8 & Nepal \\
\hline Wengkhar Rey Kaap 6 & 2006 & Khumal 6 (NR10172-2B-12-4-1-3-2) & IR13146-45-2-3/IR17492-18-6-1-1-3-3 & Nepal \\
\hline \multicolumn{5}{|l|}{ Low altitude } \\
\hline BR 153 & 1989 & BR153-2B-10-1-3 & IR578-172-2-2/BR1-2-B-19 & Bangladesh \\
\hline BW 293 & 1990 & BW 293-2 & IR2070-586/BG400-1 & Sri Lanka \\
\hline BhurReykaap 1 & 2010 & IR72102-3-115-1-3-2 & --- & IRRI \\
\hline BhurReykaap 2 & 2010 & Karjat 3 & --- & India \\
\hline BhurKambja 1 & 2010 & APO & --- & Philippines \\
\hline BhurKambja 2 & 2010 & IR70181-5-PM1-1-2-B-1 & --- & IRRI \\
\hline
\end{tabular}

Source: Javier 2007 
Traditional varieties and landraces provide the genetic basis and diversity for development of modern varieties. Extant genetic diversity depends on the initial germplasm pool and their use by farmers. Pedigree relationships between varieties help to analyze the level of genetic variation (Joshi 2005) and also determine the relative contribution of local and foreign genetic sources in variety development. Pedigree analysis of three rice varieties released in Bhutan was done. Two of the varieties, Yusi Ray Kaap- 2 and Bajo Maap-1 were bred locally while IR 64 was developed by IRRI. For the development of Yusi Ray Kaap-2, 50\% contribution came from a Japanese variety Akiyutaka. Similar to breed Bajo Maap-1, a Thai variety Gam Pai-15and a Taiwanese variety Taichung Native-1 contributed $25 \%$ each (Table 2).

\section{Outflow of germplasm}

There are not many records as far as germplasm outflow is concerned. In the 1970s and 1980s, a few germplasm exploration missions were undertaken in Bhutan by CGIAR centers such as IRRI, CIMMYT and by AVRDC and also by some interested plant collectors from Japan, Korea and USA. The exact number of germplasm collected and taken out of the country remains unrecorded and unknown. In the past, visiting scientists from CGIAR centers, countries and international organizations often collected and carried back germplasm without any problem. The gene banks of IRRI, AVRDC, CIMMYT, ICARDA and the International Crops Research Institute for the Semi-Arid Tropics (ICRISAT) hold Bhutanese germplasm. In addition, the national gene bank of Japan and some university genebanks of Japan possess germplasm from Bhutan. The Royal Botanical Gardens in Kew and Edinburgh in the UK grow and showcase many ornamental plants (Rhododendron, bamboo) from Bhutan. Bhutan's National Biodiversity Centre (NBC, holding the national genebank) is now trying to trace such germplasm and repatriate it to the national genebank in Serbithang, Thimphu. However, queries to genebanks and institutions believed to hold Bhutanese germplasm are generally ignored and information is hard to obtain.
The records available at NBC from 2009 until the middle of 2014 indicate that a total of 88 applications for a (Standard) Material Transfer Agreement were received and 85 of those were signed, mostly for academic and commercial purposes. A total of 85 samples were taken out of the country including 49 plant, 11 soil, 7 insect and 13 others. Prior to the Convention on Biological Diversity the awareness about the importance of germplasm flows, interdependency and conservation of agricultural biodiversity was low in Bhutan. With the establishment of NBC in 1998 as the umbrella agency for biodiversity conservation in the country, protocols and regulations for germplasm exchange have gradually been put in place (NCCAP 2013). As part of these efforts, the NBC has, since 2011, developed new policies, rules and regulations for the effective implementation of the International Treaty on Plant Genetic Resources for Food and Agriculture (ITPGRFA).

\section{Contributions to the multilateral system}

Bhutan is a signatory country to the International Treaty on Plant Genetic Resources for Food and Agriculture (ITPGRFA). The country is in the process of notifying the Secretariat of the ITPGRFA about its national ex situ accessions to be included in the multilateral system of the ITPGRFA through which international exchanges are facilitated. More about the Bhutanese germplasm can be found in the genebanks of CGIAR centers and in some national gene banks through which germplasm has been distributed in recent years. While detailed information on what is shared and with whom is not available, IRRI has provided information on Bhutanese rice accessions that were accessed from its genebank. From 1979 until 2013, 44 countries around the globe have accessed Bhutanese rice germplasm for research, evaluation, commercial and other purposes. Samples prior to 1994 were sent without MTA (Material Transfer Agreement). From 1994 to 2006, IRRI used the FAO MTA while materials distributed after 2007 were sent using the SMTA (Standard Material Transfer Agreement). A total of 3802 samples of 422 varieties were distributed. Among the countries accessing
Table 2 Ancestors and their origin used for developing Bhutanese rice varieties

\begin{tabular}{llll}
\hline Rice variety & Ancestor/landrace & Country of origin & Percent contribution \\
\hline Yusi Ray Kaap-2 & Naam & Bhutan & 50 \\
& Akiyutaka & Japan & 50 \\
Bajo Maap-1 & Punakha Maap & Bhutan & 50 \\
& Gam Pai-15 & Thailand & 25 \\
& Taichung Native-1 & Taiwan & 25 \\
IR64 & Gam Pai-15 & Thailand & 50 \\
& Taichung Native-1 & Taiwan & 50 \\
\hline
\end{tabular}


Fig. 1 Top 15 countries that have accessed rice germplasm of Bhutan

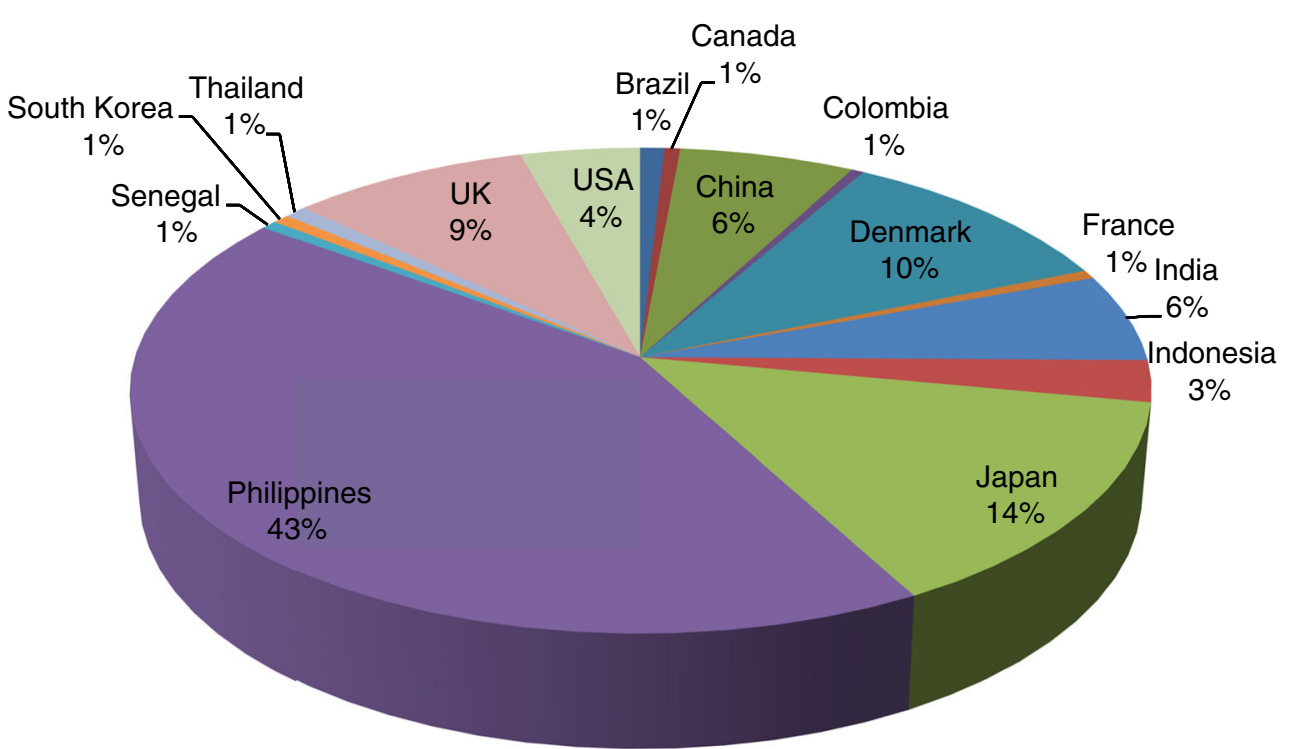

germplasm, the Philippines (Fig. 1) topped the list with 1430 samples, followed by Japan (471), Denmark (351), the UK (288) and China (211). Bhutan repatriated 351 rice accessions in 2007 from IRRI for preservation in its national gene bank.

Among the rice varieties, Phudugey was most sought after with over 100 samples distributed in more than 17 countries. Other popular Bhutanese varieties which were often accessed include Abri, Farangey, Gymbja, Yankum, Dakpa Bara, Kati, Ngabja, Dumbja, KaamMra, Zakha, Takmaru, Asu, Naam, Timburey, Maap, Sukkimey, Attey, Kochum, Toli, Sung Sung Bara, Zechum, Bjanam, Rudwa, Mansara, Champasari and WangdaKaam. It is not known if important variety innovations were developed internationally or in other countries using Bhutanese germplasm. It is doubtful if such information can ever be known, but it will be worth pursuing to determine and quantify the contribution Bhutan has made through the multilateral system of the ITPGRFA.

\section{Factors influencing germplasm exchange}

Bhutan's germplasm interdependency gradually but steadily developed in a context of changing international relations and the modernization of the country's political economy. Although the country aims to develop its capacities by relying heavily on own approaches and resources, the agricultural policies of recent decades has relied heavily on foreign resources including crop germplasm. Before 1994, plant genetic resources were considered a common heritage of mankind. The free movement of plant genetic resources across national boundaries had been instrumental in the development of modern varieties that triggered the green revolution. Today, germplasm movement is governed by international agreements that a country is bound to implement and by national legislation. In
1995, Bhutan became a Party to the Convention on Biological Diversity (CBD) which promotes the conservation of biodiversity, sustainable use of its components, and fair and equitable sharing of benefits derived from the use of genetic resources (Javier 2007). However, the CBD also restricts the movement of genetic resources for important food crops like rice. In 2003, Bhutan became a Party to the International Treaty on Plant Genetic Resources for Food and Agriculture (ITPGRFA) which established the multilateral system of exchange for important germplasm for food and agriculture. Bhutan is now preparing to contribute its germplasm to the MLS. From now on it will use the Standard MTAs for exchange of germplasm through the MLS. ITPGRFA promotes benefit sharing and recognizes farmers' rights. In 2003, Bhutan became a Party to the Cartagena Protocol, which aims to protect biological diversity from the potential risk posed by living modified organisms resulting from modern biotechnology.

In Bhutan, important national legislation has a bearing on varietal use and movement across national boundaries. The Biodiversity Act of 2003 (revised and updated in 2015) has provisions on the rights of indigenous communities over traditional knowledge. The Biodiversity Act also has a chapter on a sui generis system for the protection of plant varieties which answers the requirement of the World Trade Organization (WTO). It includes farmers' rights and exemption for research purposes. This will encourage the entry of important protected varieties developed elsewhere that may be critical during calamities or disease epidemics. In 2000, Bhutan passed the Seeds Act that promotes the development and use of improved varieties and encourages the participation of the private sector and farmers' organizations in the seed industry. It created the National Seed Board, chaired by 
the Minister of Agriculture, which presides over varietal release and use.

The main institutes involved in the exchange of crop germplasm in Bhutan are the RNR- RDCs and the NSC, while NBC serves as the overall agency for facilitation and adherence to exchange protocols. Being a relatively young organization, NBC lacks a separate set of resources and staff for the regulation of germplasm exchange. This is an institutional and administrative hindrance for the time being. The rules and regulations for germplasm exchange are being elaborated and put in place. The main agricultural stakeholders in the country tend to believe more in receiving germplasm from outside and to be restrictive in sharing genetic materials with others. While such a tendency may auger well with the country's conservation ethics, a broader view of reciprocity for global food security seems warranted given Bhutan's high dependence on foreign germplasm.

\section{Constraints and opportunities in germplasm exchange}

There are several constraints to accessing foreign germplasm as perceived by the agricultural stakeholders who were surveyed. Intellectual property right (IPR) regimes have put restrictions on access to germplasm in the regional and international arenas. Holders of germplasm have become more protective in the sharing and use of germplasm as more sovereign rights are observed. Many germplasm holders also claim poor institutional and related facilities to share genetic resources and cite the lack of inventory and knowledge as current barriers. NBC is a young agency still in the process of establishing a sound germplasm exchange system and lacks adequate resources for smooth implementation. RNR-RDCs and other stakeholders depend on the capacity of NBC for exchange. The Bhutan Agricultural and Food Regulatory Authority (BAFRA) presently has poor institutional capacity to detect and prevent foreign pests and diseases that could be entering the country along with crop germplasm.

However, opportunities abound for Bhutan to develop a clearer and more effective exchange regime by learning from other countries. There is opportunity to establish stronger and new linkages with national and international genebanks in the Himalayan region and beyond for exchange of genetic material with good adaptive potential to the particular Bhutanese conditions and related knowledge and expertise in genetic resources management and conservation. Stakeholders interviewed view such opportunities as critical measures to building the national capacity for well-targeted and continued germplasm exchange. It is also perceived that reciprocity is a must in germplasm exchange for a healthy and sustainable system for continuous crop improvement and food production. Building and strengthening the plant breeding capacity of RNR RDCs is also high on the list of critical measures mentioned by the stakeholders. Interviewees expressed that such measures should be integrated in the national agricultural policy.

\section{Conclusions}

Crop germplasm forms the foundation for food and agriculture on earth. Such germplasm, however, is not distributed evenly which necessitates germplasm flows between continents, regions, countries and research institutions. Bhutan has been receiving improved crop germplasm since it started planned agricultural development in the early 1960s. The inflow of crop germplasm is an essential input for the crop research and development agenda of the RNR RDCs. Although Bhutan's development strategy promotes self-reliance, the dependence on this type of crop germplasm is a key component of the country's political economy. Many of the newly introduced crops and crop varieties are exotic or non-traditional, for instance, cole crops, fruits and nuts. Countries like India, Nepal, Japan, Thailand, Korea, Pakistan and Bangladesh are the main source of germplasm in addition to CGIAR centres. The germplasm outflow was unrestricted prior to the creation of NBC in 1999. Procedures and protocols are now in place for a more regulated outflow and exchange of germplasm.

Bhutan has and continues to rely heavily on external genetic resources for its major food crops and agriculture overall. New germplasm of staple cereals such as rice, maize and wheat are regularly introduced, tested and used by farmers. Pedigree analysis of rice varieties grown in Bhutan showed that 15 of the 23 released varieties originate from other countries. Many of the horticultural crops, both fruits and vegetables, are new to the country. The national research system has released over 180 varieties of cereals, fruits and vegetables. Almost all of the new varieties were developed elsewhere making Bhutan heavily reliant on imported germplasm. In recent years, their value for food consumption and cash income through export has skyrocketed. Bhutan has made a small germplasm contribution to the multilateral system through the genebanks of CGIAR centers such as IRRI. However, it is not known what variety innovations were developed using the Bhutanese germplasm.

The present constraints to international germplasm exchange include stricter IPR regimes in many countries and political and regulatory difficulties in accessing external germplasm. The institutions involved in genetic resources management and exchange in Bhutan are new and lack adequate 
expertise and experience. However, opportunities exist in developing clear exchange mechanisms and new forms of (research) collaboration for more effective flows of germplasm. Learning from other countries, the Bhutanese government has made a start on improving the regulatory environment. There is scope for including additional measures in the country's agricultural policy and increasing the funding for research such as support for the conservation and improvement of traditional varieties and related traditional knowledge, for example, through participatory plant breeding.

Acknowledgments The research on interdependence was carried out under the umbrella of the project "Strengthening National Capacities to implement the International Treaty on Plant Genetic Resources for Food and Agriculture (ITPGRFA)," funded by the Directorate-General for International Cooperation, Ministry of Foreign Affairs, the Netherlands. This work was implemented as part of the CGIAR Research Programme on Climate Change, Agriculture and Food Security (CCAFS), which is carried out with support from CGIAR Fund Donors and through bilateral funding agreements. For details please visit https://ccafs.cgiar.org/donors. The views expressed in this document cannot be taken to reflect the official opinion of these organisations. We are grateful to Dr. Tashi Yangzome and Asta Tamang of the National Bioversity Center of Bhutan for their guidance and support. Similarly, our gratitude goes to N.K. Pradhan of the Council of Renewable Natural Resources Research of Bhutan for his assistance and collaboration. We thank all the other scientists and experts we talked to for their inputs, views and information. We are indebted to Dr. Madan Bhatta and Dr. B.K. Joshi of the National Agricultural Research Council of Nepal for their assistance with the pedigree analysis. We benefitted greatly from the comments and suggestions of two anonymous reviewers.

\section{Compliance with ethical standards}

Conflict of interest statement The authors declare not to have a conflict of interest.

Open Access This article is distributed under the terms of the Creative Commons Attribution 4.0 International License (http:// creativecommons.org/licenses/by/4.0/), which permits unrestricted use, distribution, and reproduction in any medium, provided you give appropriate credit to the original author(s) and the source, provide a link to the Creative Commons license, and indicate if changes were made.

\section{References}

Anonymous. (Undated). History of Bondey Farm (unpublished manuscript). Department of Agriculture, Royal Government of Bhutan, Thimphu.

Council of Renewable Natural Resources Research of Bhutan (CoRRB). (2009). An update on released and Denotified varieties of field, horticulture and Feedand fodder crops of Bhutan (1988-2008).
Thimphu: Council of Renewable Natural Resources Research of Bhutan.

Dorji, T. Y., Tamang, A. M., \& Vernooy, R. (2015). The history of the introduction and adoption of important food crops in Bhutan: rice, maize, potato and chili. Thimphu: National Biodiversity Centre Ministry of Agriculture and Forests.

Fowler, C., Smale, M. and Gaiji, S. (2000). Germplasm Flows between Developing Countries and the CGIAR: An Initial Assessment. In Global Forum on Agricultural Research/International Plant Genetic Resources Institute. Strengthening partnerships in Agricultural Research for Development in theContext of Globalisation. Proceedings of the GFAR-2000 Conference, 21 April-3 May 2000, Dresden, Germany. International Plant Genetic Resources Institute (IPGRI) under the auspices of and with the assistance of the Global Forum on Agricultural Research (GFAR), Rome, Italy, pp. 86-105.

Galluzzi, G., Halewood, M., López Noriega, I. and Vernooy, R. (2015). Twenty five years of international exchanges of plant genetic resources facilitated by the CGIAR genebanks: a case study on international interdependence. The International Treaty on Plant Genetic Resources for Food and Agriculture, Rome. Italy. Available: $\mathrm{http}: / / \mathrm{www}$.planttreaty.org/content/twenty-five-years-internationalexchanges-plant-genetic-resources-facilitated-cgiar-genebank Accessed 25 January 2016.

Ghimiray, M. (2005). Bhutan chapter of the plant genetic resources in the SAARC countries: their conservation and management. Dhaka: SAARC Agricultural Information Centre.

Ghimiray, M. (2012). An analysis of rice varietal improvement and adoption rate by farmers in Bhutan. Journal of Renewable Natural Resources of Bhutan, 10 (1), 13-24.

Ghimiray, M., \& Katwal, T. B. (2013). Crop genetic resources for food security and Adaptationto climate change: a review and way forward. Journal of Renewable Natural Resources Bhutan, 9(1), 1-19.

Javier, E. L. (2007). A review of Bhutan's Rice research program with emphasis on the low altitude zone. Thimphu: Council of Renewable Natural Resources Research of Bhutan.

Joshi, B.K. (2005). Rice Gene Pool for Tarai and Inner Tarai Areas of Nepal. Nepal Agricultural Research Journal, 6, 10-22. Available: http://narc.gov.np/publicaton/pdf/journal/Vol6/rice gene pool tarai and inner tarai areas nepal.pdf Accessed 25 January 2016.

Khoury, K. C., Achinacoy, H. A., Bjorkman, A. D., Navarro-Racines, C., Guarino, L., Flores-Palacios, X., Engels, J. M. M., Wiersema, J. H., Dempewolf, J., Sotelo, S., Ramírez-Villegas, J., Castañeda-Álvarez, N. P., Fowler, C., Jarvis, A., Rieseberg, L. H., \& Struik, P. C. (2016). Origins of food crops connects countries worldwide. Proceedings of the Royal Society B. doi:10.1098/rspb.2016.0792. Available: http://rspb.royalsocietypublishing.org/content/283/1832/20160792 Accessed 14 August 2016

National Cereals Conservation Strategic Action Plan (NCCAP). (2013). National Cereals Conservation Strategic Action Plan. Thimphu: National Biodiversity Centre, Ministry of Agriculture and Forests.

Reynolds, M. P. (Ed.). (2010). Climate change and crop production. Wallingford: CABI.

Shrestha, S. (2004). An economic impact assessment of the rice program in Bhutan. Los Baños: International Rice Research Institute.

Shrestha, S., Katwal, T. B., \& Ghalley, B. B. (2006). Impact assessment of improved maize technologies in Bhutan. Thimphu: Council for RNR Research of Bhutan.

Yadav, S. S., Redden, R., Hatfield, J. L., Lotze-Campen, H., \& Hall, A. (Eds.). (2011). Crop adaptation to climate change. Oxford: John Wiley \& Sons Ltd. 


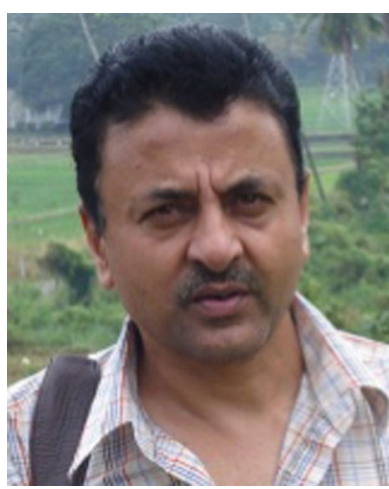

Mahesh Ghimiray is a rice specialist at the Bajo Renewable Natural Resources Research and Development Centre where he has been leading Bhutan's rice research since 2000 . He studied agriculture, plant breeding and biological diversity in Bhutan, India and the UK. He has carried out research on community-based natural resource management, the on farm conservation of agricultural biodiversity, participatory variety selection, and the history of crop management in Bhutan.

He is one of only two plant breeders in the country.

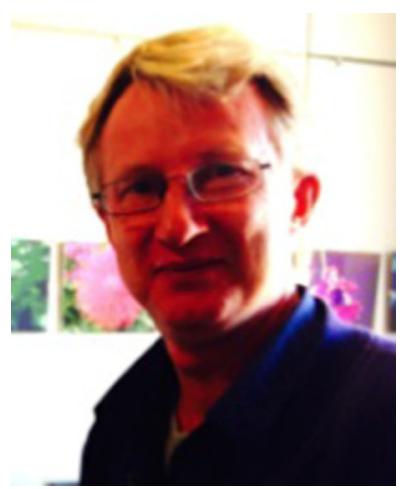

Ronnie Vernooy joined Bioversity International in October 2011. He has worked on questions related to the conservation and sustainable use of agricultural biodiversity for more than 25 years in countries such as Bhutan, China, Colombia, Cuba, Honduras, Mongolia, Nepal, Nicaragua, South Africa and Vietnam. His current work focuses on the policy and legal aspects of the safeguarding and sustainable use of plant genetic resources, both ex situ and in situ, from local to international levels. From 1992 until 2010, he was a program officer specializing in community-based natural resource management with the International Development Research Centre (IDRC), Ottawa, Canada. From 2005 to 2010, he was an adjunct professor at the College of Humanities and Development of China Agricultural University in Beijing, teaching community-based natural resource management. Before joining Bioversity International, from October 2010 to September 2011, he lived and worked in Mongolia providing support to the development of communitybased climate change adaptation and disaster risk management strategies. He has expertise in participatory action research including monitoring and evaluation, social and gender analysis, and capacity development. He has written and edited, jointly with research partners, briefs, papers, articles, book-chapters and books in English, Spanish, French, Chinese and Mongolian. 